\title{
Early-Life Social Isolation Stress Increases Kappa Opioid Receptor Responsiveness and Downregulates the Dopamine System
}

\author{
Anushree N Karkhanis ${ }^{1,2}$, Jamie H Rose', Jeffrey L Weiner ${ }^{1,2}$ and Sara R Jones, ${ }^{*, 1,2}$ \\ 'Department of Physiology and Pharmacology, Wake Forest School of Medicine, Winston-Salem, NC, USA; ${ }^{2}$ Translational Center for the \\ Neurobehavioral Study of Alcohol, Wake Forest School of Medicine, Winston-Salem, NC, USA
}

\begin{abstract}
Chronic early-life stress increases vulnerability to alcoholism and anxiety disorders during adulthood. Similarly, rats reared in social isolation (SI) during adolescence exhibit augmented ethanol intake and anxiety-like behaviors compared with group housed (GH) rats. Prior studies suggest that disruption of dopamine (DA) signaling contributes to Sl-associated behaviors, although the mechanisms underlying these alterations are not fully understood. Kappa opioid receptors (KORs) have an important role in regulating mesolimbic DA signaling, and other kinds of stressors have been shown to augment KOR function. Therefore, we tested the hypothesis that SI-induced increases in KOR function contribute to the dysregulation of NAc DA and the escalation in ethanol intake associated with SI. Our ex vivo voltammetry experiments showed that the inhibitory effects of the kappa agonist U50,488 on DA release were significantly enhanced in the NAc core and shell of SI rats. Dynorphin levels in NAc tissue were observed to be lower in SI rats. Microdialysis in freely moving rats revealed that SI was also associated with reduced baseline DA levels, and pretreatment with the KOR antagonist nor-binaltorphimine (nor-BNI) increased DA levels selectively in SI subjects. Acute ethanol elevated DA in SI and GH rats and nor-BNI pretreatment augmented this effect in SI subjects, while having no effect on ethanol-stimulated DA release in $\mathrm{GH}$ rats. Together, these data suggest that KORs may have increased responsiveness following SI, which could lead to hypodopaminergia and contribute to an increased drive to consume ethanol. Indeed, SI rats exhibited greater ethanol intake and preference and KOR blockade selectively attenuated ethanol intake in SI rats. Collectively, the findings that nor-BNI reversed SI-mediated hypodopaminergic state and escalated ethanol intake suggest that KOR antagonists may represent a promising therapeutic strategy for the treatment of alcohol use disorders, particularly in cases linked to chronic early-life stress. Neuropsychopharmacology (2016) 4I, 2263-2274; doi:I0.I038/npp.20I6.2I; published online I6 March 2016
\end{abstract}

\section{INTRODUCTION}

Chronic early-life stress, such as childhood neglect, often results in anxiety and affective disorders and increased probability of drug and alcohol abuse in adulthood (Anda et al, 2002; Strine et al, 2012; Gershon et al, 2013). Despite the deleterious health consequences associated with early-life stress, relatively little is known about the specific neurobiological adaptations that contribute to these conditions. A growing body of evidence now suggests that the mesolimbic dopamine (DA) system may have an integral role in the pathophysiology associated with childhood stress. Unfortunately, while many human and animal studies have documented profound disruptions of DA signaling associated with a wide range of chronic early-life stressors, the mechanisms underlying this dysregulation are not fully

*Correspondence: Dr SR Jones, Department of Physiology and Pharmacology, Wake Forest School of Medicine, Medical Center Boulevard, Winston-Salem, NC 27I57, USA, Tel: + I 336 7I6 8533, Fax: + 336716850 I, E-mail: srjones@wakehealth.edu

Received 22 October 2015; revised 15 January 2016; accepted 5 February 2016; accepted article preview online 10 February 2016 understood. Therefore, we employed a well-established rodent adolescent social isolation (SI) model of chronic early-life stress that alters many behaviors linked with increased vulnerability to alcohol use disorders (AUDs; eg, increases in anxiety-like behaviors and in ethanol intake and preference; McCool and Chappell, 2009; Chappell et al, 2013) to examine possible mechanisms responsible for the dysregulation in mesolimbic DA signaling associated with this model (Yorgason et al, 2013).

The nucleus accumbens (NAc) is known to have a critical role in motivated behaviors and reward seeking via modulation of DA levels (Sulzer, 2011). Additionally, the NAc is implicated in the modulation of stress and anxietylike negative affective behaviors (Radke and Gewirtz, 2012). Kappa opioid receptors (KORs) are located presynaptically on DA terminals and suppress DA release in the NAc (Werling et al, 1988; Svingos et al, 2001; Ebner et al, 2010). Previous data suggest that exposure to chronic stress, such as repeated withdrawal from chronic intermittent ethanol (CIE) exposure, leads to prolonged activation of KORs (Walker and Koob, 2008), possibly contributing to reduced DA function, which is positively correlated with negative affect 


\section{a}

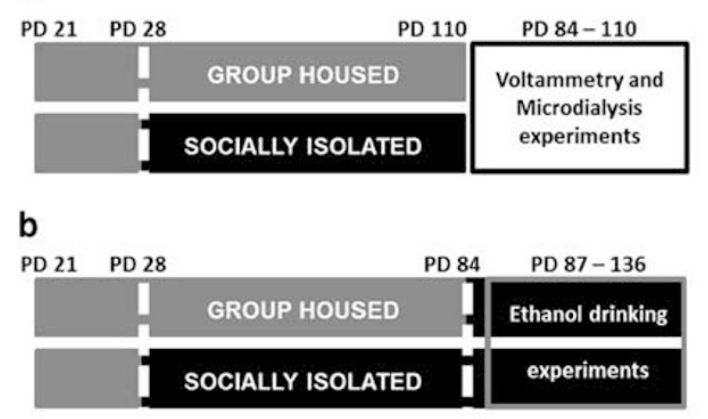

C

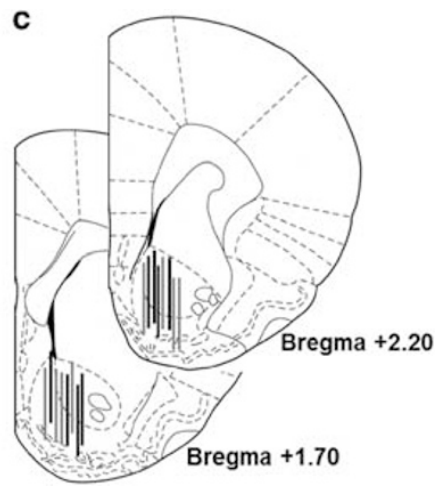

Figure I (a) A schematic of the experimental paradigm. Male, Long-Evans rats arrived at the facility on postnatal day (PD 2I) and were maintained in group housing to acclimate for I week. On PD 28, half the rats were housed individually while the other half remained in group housing. ELISA, voltammetry, and microdialysis experiments were conducted between PD 84 and PD I I 0. (b) After the housing paradigm was completed, all rats were single housed on PD 84. Ethanol drinking experiments began on PD 87 and continued for 7 weeks. (c) Coronal sections showing microdialysis probe locations. Microdialysis probes were inserted in the NAc using the rat atlas by Paxinos and Watson (2007).

(see Koob et al, 2014 for a review). Elevations in intra-cranial self-stimulation (ICSS) thresholds are associated with anhedonia, and a recent study showed that prolonged activation of KORs resulted in significantly elevated ICSS thresholds (Chartoff et al, 2016). Notably, negative affective states such as anhedonia facilitate motivation to increase the intake of drugs (Baarendse et al, 2014).

Stress increases the levels of dynorphin (Nabeshima et al, 1992; Land et al, 2008; Bruchas et al, 2010), which is an endogenous KOR ligand (Chavkin et al, 1982). Both repeated forced swim stress and pharmacological activation of KORs with U50,488 increases ethanol consumption in mice (Sperling et al, 2010; Rose et al, 2015). CIE exposure and withdrawal lead to increases in anxiety-like and anhedonic behaviors in addition to promoting an escalation in ethanol intake (Berger et al, 2013). Dynorphin A and KOR signaling is increased in ethanol-dependent adult rats (Kissler et al, 2014) that may contribute to the anhedonia associated with withdrawal. Abused drugs (including ethanol) can elevate DA levels in the NAc (Di Chiara and Imperato, 1988; Woods and Meyer, 1991; Yim et al, 1998; Suto et al, 2010) and potentially alleviate withdrawal-associated anhedonic states. Consistent with this, activation of KORs increases drug seeking and pharmacological inactivation of the dynorphin/ KOR system reduces drug seeking during withdrawal. For example, blockade of KORs with nor-binaltorphimine (nor-BNI) attenuates the augmented ethanol intake observed in adult-dependent animals (Berger et al, 2013). KOR blockade also reduces motivation for heroin and ethanol intake in adult-dependent animals, as measured by progressive ratio performance (Walker and Koob, 2008; Schlosburg et al, 2013). These studies suggest that decreasing KOR activity may represent a promising treatment for AUDs.

The goal of the current study was to investigate the possible role of KORs in some of the behavioral and neurobiological changes that manifest in SI animals. Specifically, it was hypothesized that the stress associated with adolescent SI would increase dynorphin/KOR system function and contribute to the alterations in NAc DA signaling and the escalation in ethanol intake observed with this model of early-life stress. Quantification of dynorphin in
NAc tissue using ELISA showed lower content in SI compared with group housed $(\mathrm{GH})$ rats. Ex vivo voltammetry and in vivo microdialysis in freely moving animals were used to examine changes in NAc KOR-mediated DA signaling following chronic adolescent stress and to investigate the effects of KOR blockade on baseline and ethanolinduced changes in NAc DA levels in SI and GH animals. KORs were observed to be functionally hyperactive in SI rats, and DA levels at baseline were lower in SI compared with $\mathrm{GH}$ rats. We also used an intermittent ethanol drinking paradigm to show that SI animals had significantly greater intake and preference compared with $\mathrm{GH}$ animals, effects that were selectively reduced following KOR blockade.

\section{MATERIALS AND METHODS}

\section{Group and Isolation Housing}

Male Long-Evans rats were purchased from Harlan at PD 21. At PD 28, following a week of acclimation in standard housing conditions (four animals per cage, food and water ad libitum; 12-h light/dark cycle), rats were randomly assigned to one of the two experimental groups: group housed (GH; 4/cage; guinea pig cages) and socially isolated (SI; 1/cage; rat cages). Housing procedures were identical to those used in a previous study (Karkhanis et al, 2014). Rats were maintained in their respective housing conditions for at least 8 weeks before ex vivo voltammetry, in vivo microdialysis, and ethanol drinking experiments. An experimental time line is shown in Figure 1a (voltammetry and microdialysis) and Figure 1b (ethanol drinking). A total of four cohorts were used in the current study; one each for voltammetry and drinking and two for microdialysis experiments.

\section{Ex Vivo Fast Scan Cyclic Voltammetry (FSCV)}

Ex vivo FSCV was used to characterize the functionality of KORs in the NAc of SI (core, $n=6$; shell, $n=7$ ) and GH (core, $n=7$; shell, $n=7$ ) rats following the housing paradigm (between PD 84 and PD 110). Briefly, rats were killed and their brains were rapidly removed and prepared as described 
previously (John and Jones, 2007). A vibrating tissue slicer was used to prepare $400-\mu \mathrm{m}$ thick coronal brain sections containing NAc. These slices were immersed in oxygenated artificial cerebrospinal fluid $\left(32^{\circ} \mathrm{C}\right)$ containing: $126 \mathrm{mM}$ $\mathrm{NaCl}, 2.5 \mathrm{mM}$ KCl, $1.2 \mathrm{mM} \mathrm{NaH} \mathrm{PO}_{4}, 2.4 \mathrm{mM} \mathrm{CaCl}$, $1.2 \mathrm{mM} \mathrm{MgCl}_{2}, 25 \mathrm{mM} \mathrm{NaHCO}, 11 \mathrm{mM}$ glucose, and $0.4 \mathrm{mM}$ L-ascorbic acid, and $\mathrm{pH}$ was adjusted to 7.4.

Endogenous DA release was evoked by single electrical pulse stimulation (monophasict, $4 \mathrm{~ms}, 350 \mu \mathrm{A}$ ) applied to the tissue every $5 \mathrm{~min}$. Extracellular DA concentration was recorded by applying a triangular waveform $(-0.4$ to +1.2 and back to $-0.4 \mathrm{~V}, \mathrm{Ag} v \mathrm{AgCl}$ ) at the rate of $400 \mathrm{~V} / \mathrm{s}$. Extracellular concentrations of DA were assessed by comparing the current at the peak oxidation potential for DA with electrode calibrations of known concentrations of DA $(3 \mu \mathrm{M})$. Once the extracellular DA response was stable for three consecutive stimulations, a cumulative concentration response curve of the KOR agonist, U50,488 (10, 30, 100, $300,1000 \mathrm{nM}$ ), was run by bath applying the drug to NAc slices. All FSCV data were analyzed using the Demon Voltammetry and Analysis software (Yorgason et al, 2011). DA-stimulated release parameters were determined from stabilized signals using a Michaelis-Menten kinetics-based algorithm (Ferris et al, 2013).

\section{Microdialysis}

Microdialysis procedures were similar to those described in a prior study (Karkhanis et al, 2014). Briefly, after the 8-week housing paradigm, rats (between PD 84 and PD 110) were implanted unilaterally with a guide cannula (MD-2250; BASi Instruments, West Lafayette, IN) and a microdialysis probe (2 mm; MD-2200, BASi Instruments) in the NAc (anterior, +2.2; lateral, +0.7; ventral, -5.4 with respect to bregma; Figure 1b) in an aseptic surgery. The postsurgery recovery time was between 42 and $48 \mathrm{~h}$. In the previous study (Karkhanis et al, 2014), the recovery time was 18-24 h, and DA levels did not significantly differ between SI and GH rats. A longer recovery time after the surgery has been associated with increased stability of baseline DA levels (Borland et al, 2005). All dialysate samples were collected with an interval of $20 \mathrm{~min}$ and were collected for $2 \mathrm{~h}$ prior (baseline) to ethanol administration and $100 \mathrm{~min}$ after. Samples were frozen at $-80^{\circ} \mathrm{C}$ until analysis using high-performance liquid chromatography. On day 1 of the experiment, rats $(\mathrm{GH}, n=8$; SI, $n=8)$ were injected with ethanol ( $1 \mathrm{~g} / \mathrm{kg}$; i.p.). At the end of day 1 , nor-BNI $(10 \mathrm{mg} / \mathrm{kg}$; i.p.) was administered to both $\mathrm{GH}(n=7)$ and SI $(n=7)$ rats. On day 2 of the experiment, once stable baseline DA levels were established, ethanol $(1 \mathrm{~g} / \mathrm{kg}$; i.p.) was administered $(22-24 \mathrm{~h}$ after nor-BNI administration). Control experiments without nor-BNI were conducted in a separate group of animals (GH, $n=6$; SI, $n=6)$ during which ethanol ( $1 \mathrm{~g} / \mathrm{kg}$; i.p.) was administered on 2 consecutive days.

\section{Ethanol Drinking Procedure}

Following the 8-week housing paradigm, the effect of housing condition was assessed on ethanol consumption using an intermittent access, two-bottle choice paradigm. Importantly, all rats (GH, $n=7$; SI, $n=8$ ) were singly housed on PD 84 and remained in these conditions until the completion of the drinking paradigm. Rats were given access to $20 \%$ ethanol (v/v) and water for $24 \mathrm{~h}$ every Monday, Wednesday, and Friday with access to only water on the remaining days. This procedure was conducted for 7 consecutive weeks. Each Thursday, all animals received a saline injection. This paradigm was continued until at least 3 weeks of stable ethanol intake was observed (7 weeks). To assess the effect of KOR antagonism on drinking behaviors, nor-BNI (10 mg/kg; i.p.) was administered during week 7 (Thursday), $24 \mathrm{~h}$ prior to the last drinking session. Fluid intake was measured $30 \mathrm{~min}$ after the bottle exchange on each ethanol drinking day. The intermittent drinking paradigm has previously been shown to produce relatively high levels of ethanol intake in male Long-Evans rats (Wise, 1973; Simms et al, 2008). Furthermore, this drinking paradigm has been shown to engender elevated ethanol intake in SI compared with GH rats (Chappell et al, 2013; Skelly et al, 2015).

\section{Statistical Analysis}

All statistical analyses were conducted using GraphPad Prism 5 (GraphPad Software, La Jolla, CA). The voltammetry data (concentration response curve) were analyzed using repeated measures (RM) two-way analysis of variance (ANOVA). The dependent variable was $[\mathrm{DA}] / \mathrm{p}$ and the independent variables were housing condition and U50,488 concentration. The baseline and ethanol microdialysis data were analyzed using RM two-way ANOVA. The two independent variables were time and housing condition. The dependent variable was extracellular levels of DA. For the drinking data, ethanol intake and preference ratio were analyzed using RM two-way ANOVA with week and housing condition as factors. All ANOVAs were followed by Bonferroni's post-hoc analysis. A two-tailed Student's $t$-test was used to compare $\mathrm{EC}_{50}$ between $\mathrm{SI}$ and $\mathrm{GH}$ rats. A paired two-tailed Student's $t$-test was used to compare preand post-nor-BNI ethanol intake and preference. All data are reported as mean \pm SEM. The significance level for all statistical measures was set at $p<0.05$.

\section{RESULTS}

\section{SI-Induced Increase in DA Release and Uptake in the NAc Core and Shell}

DA transmission in the NAc core and shell of SI and GH animals was examined by quantifying electrically stimulated DA release and DA uptake using ex vivo voltammetry. The color plot generated by a single 4-ms electrical stimulation in the NAc core slice and its matched concentration $v s$ time traces showing DA release are shown in Figure $2 \mathrm{a}$ and $\mathrm{b}$ respectively. Electrically stimulated DA release (Figure 2c; $\left.\mathrm{GH}=550.8 \pm 35.8 ; \mathrm{SI}=981.7 \pm 78.6 ; t_{11}=5.25 ; p<0.001\right)$ and uptake (Figure 2d; $\mathrm{GH}=1431 \pm 130.9 ; \quad \mathrm{SI}=2808 \pm 282.5$; $\left.t_{11}=4.65 ; p<0.001\right)$ were significantly greater in the NAc core of SI compared with $\mathrm{GH}$ animals. Figure $2 \mathrm{e}$ and $\mathrm{f}$ illustrate the color plot and its matched DA traces, respectively, before, during, and after electrical stimulation in the NAc shell. Similar to NAc core, SI resulted in augmented stimulated DA release (Figure 2g; GH $=518.1 \pm$ 73.5; $\left.\mathrm{SI}=905.8 \pm 101.7 ; \quad t_{12}=3.089 ; \quad p<0.01\right)$ and uptake 

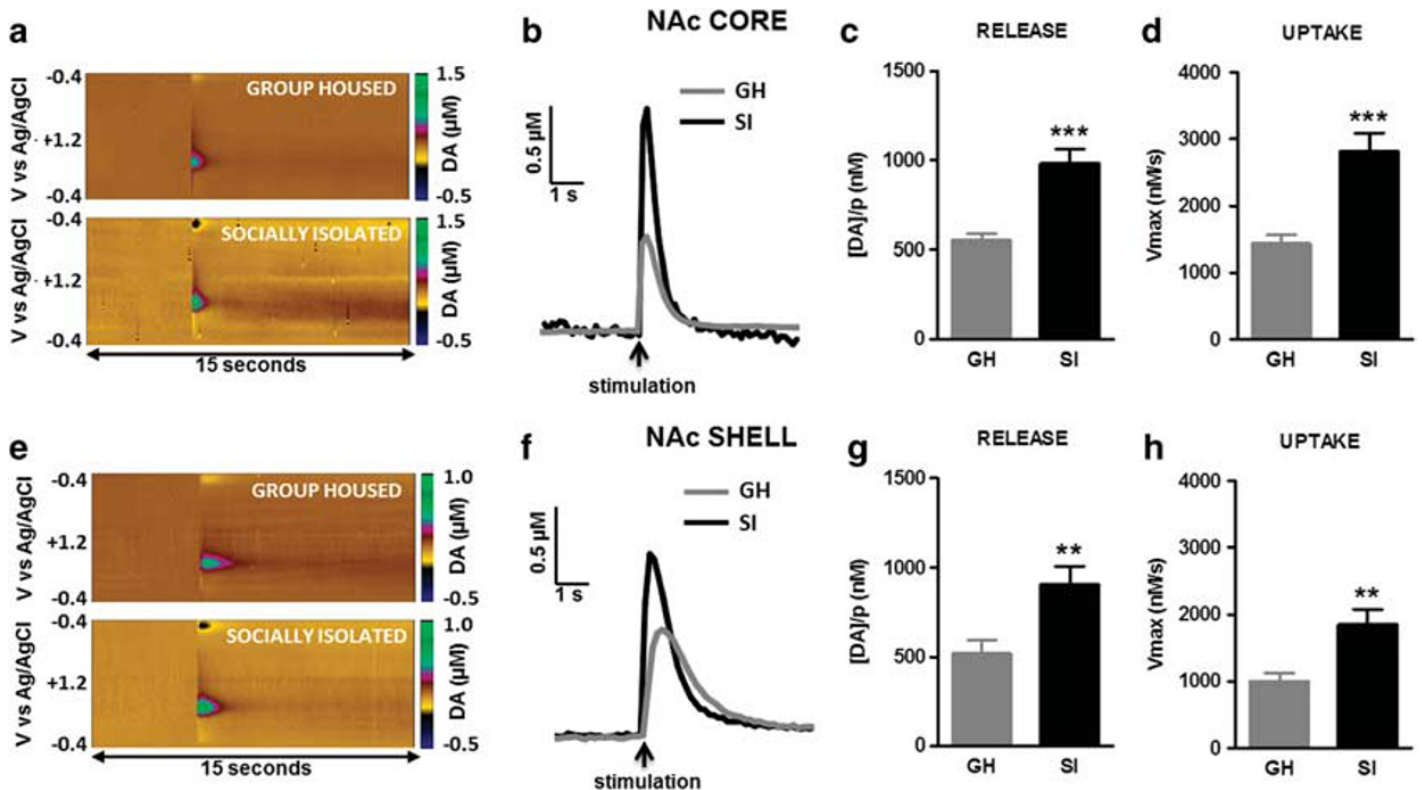

Figure 2 Social isolation facilitated DA release and uptake in the NAc core (a-d) and shell (e-h) as measured using voltammetry. Background subtracted color plots (a: GH, top; Sl, bottom; $x$ axis: time, y axis: voltage, $z$ axis: current) along with corresponding DA traces illustrating electrically stimulated DA release (peak) in GH (red) and SI (blue) rats (b) in the NAc core. (c) DA release per pulse was significantly increased in SI compared with GH animals. (d) Social isolation resulted in facilitated DA uptake rates. Background subtracted color plots (e: GH, top; SI, bottom; $x$ axis: time, $y$ axis: voltage, $z$ axis: current) along with corresponding DA traces illustrating electrically stimulated DA release (peak) in GH (red) and SI (blue) rats (f) in the NAc shell. (g) DA release per pulse was significantly augmented in SI compared with GH animals. (h) Social isolation resulted in increased DA uptake rates. NAc core: GH, $n=7 ; \mathrm{Sl}, n=6$. NAc shell: $\mathrm{GH}, n=7 ; \mathrm{SI}, n=7$. *** $p<0.0 \mathrm{I} ; *^{*} * * 0.00 \mathrm{I}$. A full color version of this figure is available at the Neuropsychopharmacology journal online.

(Figure $2 \mathrm{~h} ; \mathrm{GH}=1003 \pm 113.8 ; \mathrm{SI}=1846 \pm 225.5 ; t_{12}=3.33$; $p<0.01)$ in the NAc shell.

\section{SI Increases KOR Responsiveness in the NAc Core and Shell}

Functional responsiveness of KORs in SI and GH rats was examined by measuring the DA-decreasing effects of U50,488 using voltammetry. U50,488 decreased DA release significantly more in slices from SI compared with GH animals in both the NAc core (Figure $3 a$ and $b$, percentage of baseline DA release; Figure $3 \mathrm{c}$ and d, raw DA release) and shell (Figure $3 e$ and $\mathrm{f}$, percentage of baseline DA release; Figure $3 \mathrm{~g}$ and $\mathrm{h}$, raw DA release). An overall housing (Figure 3a; $\left.\mathrm{F}_{(1,11)}=5.40 ; \quad p<0.05\right)$ and concentration (Figure 3a; $\mathrm{F}_{(4,11)}=23.49 ; p<0.001$ ) effect was observed in the core when the percentage of baseline DA release was compared between GH and SI rats. The interaction between the two variables was not significant (Figure 3a; $\mathrm{F}_{(4,44)}=0.66$; $p>0.05)$. When the maximal decrease in DA release in the NAc core $(1 \mu \mathrm{M}$; highest concentration of U50,488 used) was compared with baseline, the percentage of decrease was found to be significantly greater in SI compared with GH animals (Figure 3b left; $\mathrm{GH}=23.9 \pm 7.1 ; \mathrm{SI}=50.1 \pm 9.0$; $\left.t_{11}=2.32 ; p<0.05\right)$. The $\mathrm{EC}_{50}$ of U50,488 was observed to be significantly lower in SI animals (Figure $3 \mathrm{~b}$ right; $\left.\mathrm{GH}=0.33 \pm .05 ; \mathrm{SI}=0.12 \pm 0.03 ; t_{11}=3.21 ; p<0.01\right)$. Upon comparing the raw DA release in the NAc core of SI and GH animals, a main effect of housing (Figure $3 \mathrm{~b} ; \mathrm{F}_{(1,11)}=7.06$; $p<0.05$ ) and concentration (Figure 3b; $\mathrm{F}_{(5,11)}=20.79$; $p<0.001$ ) in addition to an interaction (Figure 3b; $\left.\mathrm{F}_{(5,55)}=4.81 ; \quad p<0.01\right)$ was observed. Post-hoc analysis showed that DA release was attenuated significantly more in SI compared with $\mathrm{GH}$ rats at the $1 \mu \mathrm{M}$ concentration of U50,488. In the NAc, when the maximal KOR activationinduced decrease in DA release (raw data) was compared with baseline, the reduction was found to be significantly greater in SI compared with GH animals (Figure 3d left; $\left.\mathrm{GH}=127.8 \pm 40.9 ; \mathrm{SI}=443.5 \pm 96.6 ; t_{11}=3.18 ; p<0.01\right)$. The $\mathrm{EC}_{50}$ of U50,488 was observed to be significantly lower in SI animals (Figure $3 \mathrm{~d}$ right; $\mathrm{GH}=0.31 \pm 0.03$; $\mathrm{SI}=0.16 \pm 0.06$; $t_{11}=2.30 ; \quad p<0.05$ ). An overall housing (Figure 3e; $\mathrm{F}_{(1,12)}=5.54 ; \quad p<0.05$ ) and concentration (Figure 3e; $\left.\mathrm{F}_{(4,12)}=61.34 ; p<0.001\right)$ effect was observed in the NAc shell when the percentage of baseline DA release was compared between GH and SI rats. The interaction between the two variables was not significant (Figure 3e; $\mathrm{F}_{(4,48)}=2.49$; $p>0.05)$. Post-hoc analysis showed a significant difference at the $0.03 \mu \mathrm{M}$ concentration of U50,488. In the NAc, the maximal reduction in DA release (percentage of baseline) was not significantly different in SI and GH animals (Figure 3f left; $\mathrm{GH}=44.9 \pm 5.2 ; \mathrm{SI}=52.0 \pm 5.2 ; t_{12}=0.96$; $p>0.05)$. This is because these data were normalized to baseline DA release and the two curves meet at the $1 \mu \mathrm{M}$ concentration. However, the $\mathrm{EC}_{50}$ of U50,488 was observed to be significantly lower in SI compared with GH rats (Figure 3f right; $\mathrm{GH}=0.31 \pm .03 ; \mathrm{SI}=0.10 \pm 0.02 ; t_{12}=5.38$; $p<0.001)$. Upon comparing the raw DA release in the NAc shell of SI and GH animals, a main effect of concentration (Figure 3g; $\mathrm{F}_{(5,12)}=35.85 ; p<0.001$ ) but not of housing (Figure 3g; $\mathrm{F}_{(1,12)}=2.96 ; p>0.05$ ) was observed. Furthermore, an interaction (Figure 3g; $\mathrm{F}_{(5,60)}=3.03 ; p<0.05$ ) between the two variables was observed. When the maximal decrease in DA release in the NAc shell was compared with 
a
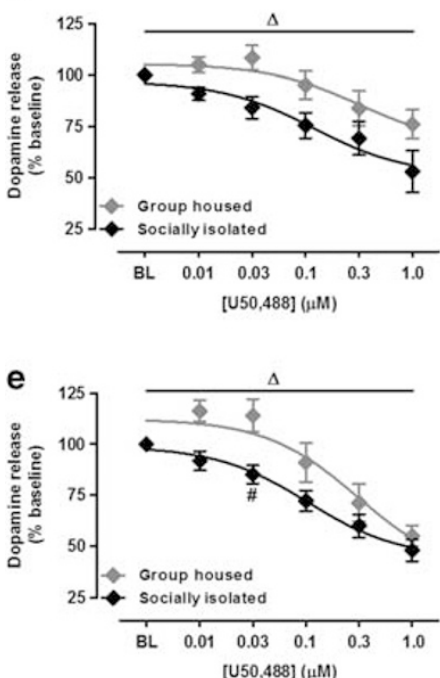

b
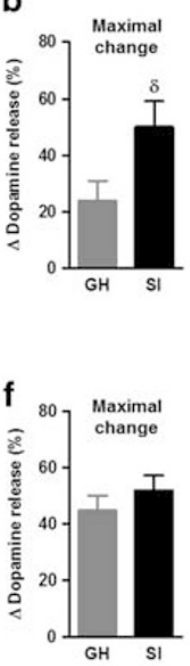

NAC CORE
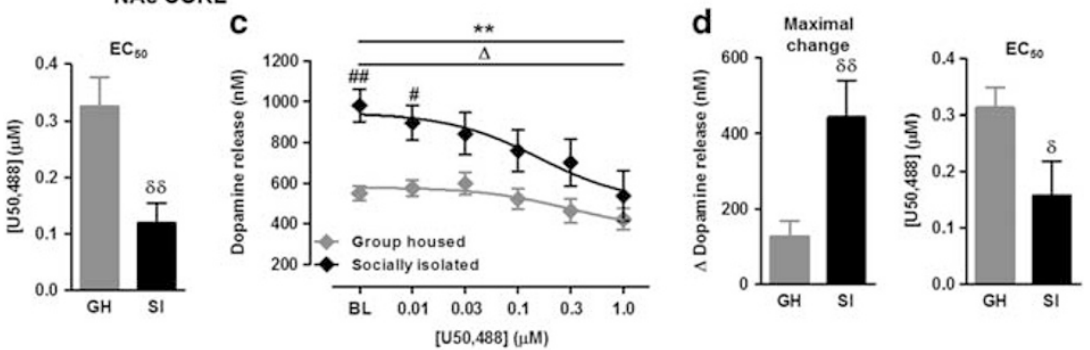

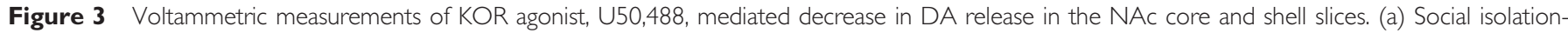

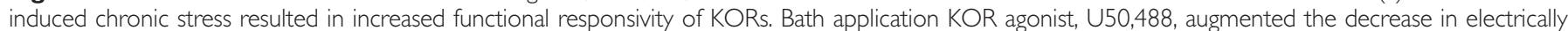

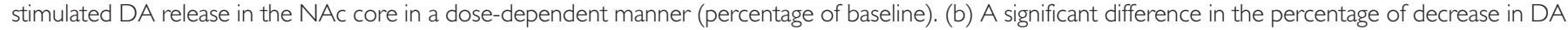

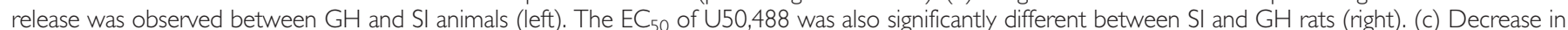

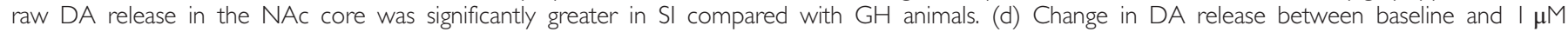

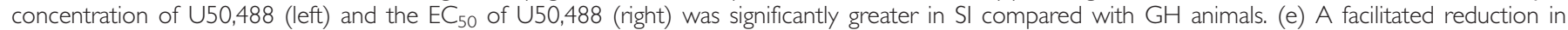

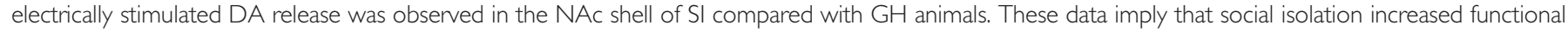

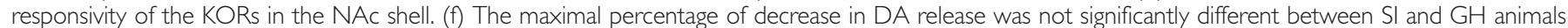

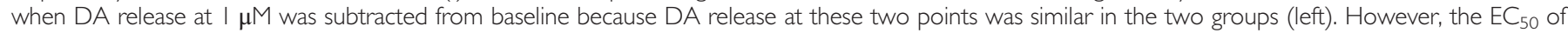

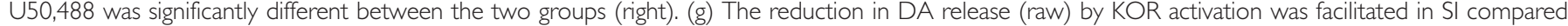

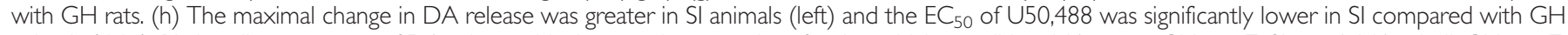

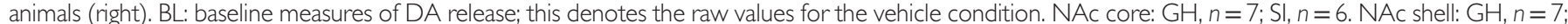

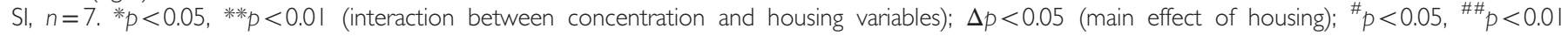

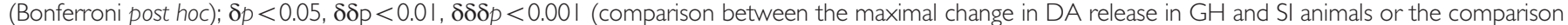
between the $\mathrm{EC}_{50}$ of $\mathrm{U} 50,488$ in $\mathrm{GH}$ and $\mathrm{SI}$ animals).

baseline, the attenuation in raw DA release was found to be significantly greater in SI compared with $\mathrm{GH}$ animals (Figure $3 \mathrm{~h}$ left; $\mathrm{GH}=226.8 \pm 32.7 ; \mathrm{SI}=444.6 \pm 25.6$; $\left.t_{12}=5.24 ; p<0.001\right)$. The $\mathrm{EC}_{50}$ of $\mathrm{U} 50,488$ was significantly lower in SI animals (Figure $3 \mathrm{~h}$ right; $\mathrm{GH}=0.32 \pm .07$; $\left.\mathrm{SI}=0.10 \pm 0.05 ; t_{12}=2.46 ; p<0.05\right)$.

\section{Nor-BNI Administration Elevated the Low Baseline DA Levels in SI Rats}

Because no significant differences were observed in the core and shell regions of NAc in the experiments above, these sub-regions were not differentiated in the microdialysis experiments below. Extracellular DA levels (baseline levels prior to ethanol administration) on 2 consecutive control days (Figure $4 \mathrm{a}$ ) and DA levels before and after nor-BNI treatment (Figure 4b) were examined. Extracellular DA levels in SI animals were significantly lower than those in GH animals on both control days (Figure 4a; housing effect; $\left.\mathrm{F}_{(1,11)}=15.97 ; p<0.01\right)$. No differences between control days 1 and 2 were found in either the GH or the SI group. A significant treatment effect (Figure 4b; $\mathrm{F}_{(1,14)}=16.31$; $p<0.01$ ) and an interaction between the housing ( $\mathrm{GH} v s$ $\mathrm{SI}$ ) and treatment (before $v s$ after nor-BNI; $10 \mathrm{mg} / \mathrm{kg}$ i.p.) variables was observed $\left(\mathrm{F}_{(1,14)}=13.99 ; p<0.01\right)$. Post-hoc analysis revealed that baseline DA levels were significantly lower in SI compared with GH animals $(p<0.01)$ and were greater in SI animals following the nor-BNI pretreatment compared with levels before nor-BNI administration $(p<0.001)$. No such change was noted in GH animals.

\section{Ethanol-Induced DA Release is Augmented in SI Rats Pretreated with nor-BNI}

Based on the observations that nor-BNI pretreatment elevates DA levels in SI, but not in GH rats, it was hypothesized that nor-BNI pretreatment would have differential effects on acute ethanol-induced elevation of DA levels in the NAc of GH and SI rats. GH and SI rats were treated with nor-BNI $(10 \mathrm{mg} / \mathrm{kg})$ or vehicle $22-24 \mathrm{~h}$ prior to ethanol $(1 \mathrm{~g} / \mathrm{kg})$ administration. Similar to our previous results (Karkhanis et al, 2014), acute ethanol $(1 \mathrm{~g} / \mathrm{kg})$ induced an equivocal, albeit significant, elevation in DA in the NAc of $\mathrm{GH}$ and SI rats (Figure 4c, $\mathrm{GH}_{\text {control }}=128.6 \% \pm 7.7$; Figure $\left.4 \mathrm{~d}, \mathrm{SI}_{\text {control }}=135.2 \% \pm 5.7\right)$. Despite the lack of difference in SI and GH rats, we chose to use this dose of ethanol to avoid a ceiling effect as we hypothesized that the increased function of KORs might mask a greater effect of ethanol on DA in SI animals. In the presence of nor-BNI, acute ethanol $(1 \mathrm{~g} / \mathrm{kg})$ increased DA levels in $\mathrm{GH}$ and SI animals (Figure $4 \mathrm{c}, \mathrm{GH}_{\text {nor-BNI }}=137.3 \% \pm 8.3$; Figure $4 \mathrm{~d}$, $\left.\mathrm{SI}_{\text {nor-BNI }}=172.6 \% \pm 10.3\right)$. In the $\mathrm{GH}$ animals, nor-BNI pretreatment did not affect ethanol-induced DA release (Figure $4 \mathrm{c}$, percentage of change from baseline; Figure $4 \mathrm{e}$; 

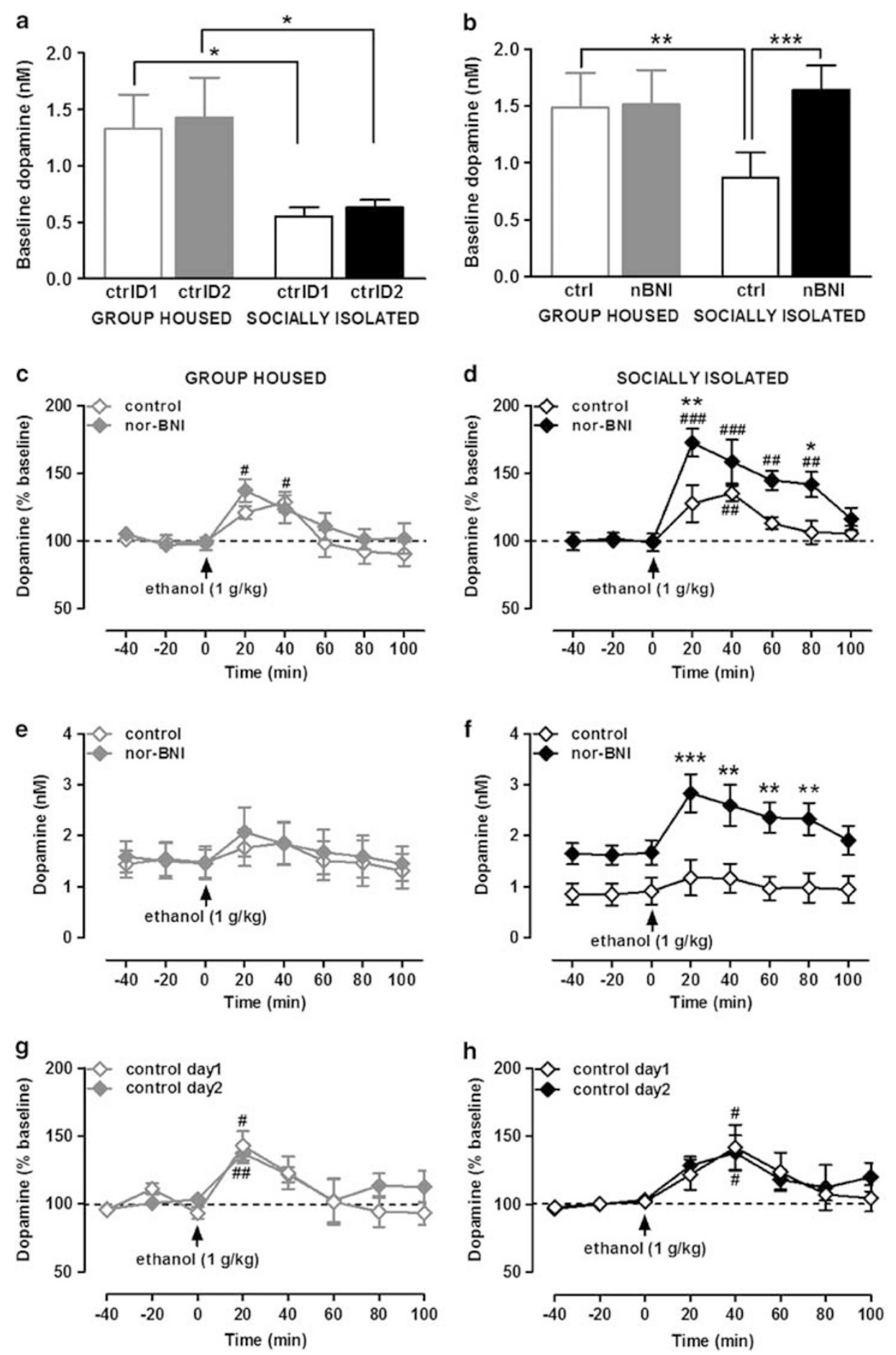

Figure 4 KOR blockade enhances ethanol-mediated extracellular DA response in the NAc in SI but not in GH rats (microdialysis). (a) DA levels (baseline levels prior to ethanol administration) in the NAc are stable across the 2 days of the microdialysis experiments in both GH (open red bar, control day I; solid red bar, control day 2) and SI (open blue bar, control day I; solid blue bar, control day 2) animals. (b) Administration of nor-BNI, KOR antagonist, increased baseline DA levels (prior to ethanol administration) in $\mathrm{SI}$ (blue bars), but not in $\mathrm{GH}$ (red bars) animals. These data suggest that social isolation during adolescence resulted in supersensitive KORs. (c) Ethanol (I g/kg) induced DA response in $\mathrm{GH}$ animals before (open red symbols) and $24 \mathrm{~h}$ after (solid red symbols) nor-BNI administration as a percentage of baseline. No difference between the two groups was observed. (d) Ethanol (I g/kg) induced DA response in SI rats before (open blue symbols) and $24 \mathrm{~h}$ after (solid blue symbols) nor-BNI administration as a percentage of baseline. Nor-BNI pretreatment augmented the ethanol-mediated DA response in SI animals. (e) The raw value curve of ethanol $(\mathrm{I} \mathrm{g} / \mathrm{kg}$ ) mediated DA response in $\mathrm{GH}$ rats (control; open blue symbols) and $24 \mathrm{~h}$ after nor-BNI administration (solid blue symbols). Ethanol-induced DA elevation was not different in the absence and presence of nor-BNI. (f) The raw value curve of ethanol $(\mathrm{l} \mathrm{g} / \mathrm{kg}$ ) mediated DA response in SI rats (control; open blue symbols) and $24 \mathrm{~h}$ after nor-BNI administration (solid blue symbols). Ethanol-induced DA elevation was enhanced in the presence of nor-BNI. These data suggest that KORs become sensitized following social isolation during adolescence. A I-g/kg dose of ethanol administered on 2 consecutive days resulted in a similar DA response in both $\mathrm{GH}(\mathrm{g})$ and $\mathrm{SI}(\mathrm{h})$ rats. n-BNI experiments: $\mathrm{GH}, n=8 ; \mathrm{Sl}, n=8$. Control experiments: $\mathrm{GH}, n=6 ; \mathrm{SI}, n=6$. * $p<0.05 ;{ }^{* *} p<0.0$ I; **** $p<0.00$ I (comparison between before and after nor-BNI treatment). ${ }^{\#} p<0.05 ;{ }^{\# \#} p<0.0$ I; ${ }^{\# \# \#} p<0.00$ I (effect of acute ethanol within the respective group). A full color version of this figure is available at the Neuropsychopharmacology joumal online. 
raw data showing DA levels over time). However, in the SI animals KOR blockade augmented ethanol-induced DA release (Figure $4 \mathrm{~d}$ ). An interaction between the time and treatment parameters $\left(\mathrm{F}_{(7,98)}=3.18, p<0.01\right)$, a main effect of treatment $\left(\mathrm{F}_{(1,14)}=8.08, p<0.05\right)$, and a main effect of time $\left(\mathrm{F}_{(7,14)}=16.82, p<0.001\right)$ was observed. Post-hoc test revealed a significant difference between DA elevations in the presence and absence of nor-BNI in SI rats 20 and 80 min after ethanol administration. Because the baseline DA levels were significantly different before and after nor-BNI treatment, ethanol-mediated elevations in DA levels (in $\mathrm{nM}$ ) were compared before and after nor-BNI pretreatment in SI (Figure 4f). This comparison showed an interaction between time and treatment parameters $\left(\mathrm{F}_{(7,98)}=5.65, p<0.001\right)$ and a main effect of the treatment $\left(\mathrm{F}_{(1,14)}=9.25, p<0.01\right)$ and time $\left(\mathrm{F}_{(7,14)}=15.59, p<0.001\right)$. Post-hoc analysis revealed that this difference between norBNI treated and untreated animals was significant starting 20 min postethanol administration and remained significant until $80 \mathrm{~min}$. Administration of ethanol $(1 \mathrm{~g} / \mathrm{kg})$ on consecutive days resulted in an equivocal, albeit significant, DA elevation on both days in GH (Figure 4g; day $1=142.7 \pm 10.7$; day $2=137.3 \pm 7.3$ ) and SI (Figure $4 \mathrm{~h}$; day $1=141.7 \pm 16.7$; day $2=137.8 \pm 12.8)$ animals.

\section{Greater Ethanol Consumption and Preference in SI Rats is Normalized with KOR Blockade}

As in our prior study (Chappell et al, 2013), intermittent ethanol self-administration increased over time in both groups, but ethanol intake was significantly greater in SI rats across the 7-week drinking regimen (Figure 5a; housing: $\mathrm{F}_{(1,13)}=5.72, p<0.05$; week: $\left.\mathrm{F}_{(6,13)}=3.68, p<0.01\right)$. A paired two-tailed Student's $t$-test was used to analyze pre- and post-nor-BNI ethanol intake in GH and SI animals. A within-group comparison of week 7 ethanol drinking and post-nor-BNI drinking revealed no effect of nor-BNI on ethanol intake in $\mathrm{GH}$ subjects $\left(t_{6}=1.01 ; p>0.05\right.$; Figure $\left.5 \mathrm{~b}\right)$; however, nor-BNI pretreatment significantly reduced ethanol intake in SI rats to levels comparable to those observed in $\mathrm{GH}$ subjects $\left(t_{7}=3.43 ; p<0.05\right.$; Figure $\left.5 \mathrm{~b}\right)$.

An analysis of ethanol preference revealed similar findings, with a main effect of housing $\left(\mathrm{F}_{(1,13)}=5.80 ; p<0.05\right.$; Figure $5 \mathrm{c})$ and drinking week $\left(\mathrm{F}_{(6,13)}=6.93 ; p<0.001\right.$; Figure 5c), with SI rats exhibiting greater ethanol preference. Comparison of week 7 and post-nor-BNI ethanol preference using a paired two-tailed Student's $t$-test revealed no effect of nor-BNI in GH rats $\left(t_{6}=0.08, p>0.05\right.$, Figure $\left.5 \mathrm{~d}\right)$ but a significant reduction in the ethanol preference of SI rats after nor-BNI treatment $\left(t_{7}=4.77, p<0.01\right.$, Figure $\left.5 \mathrm{~d}\right)$.

\section{DISCUSSION}

Chronic adolescent SI increases anxiety-like behaviors and ethanol consumption during adulthood and significantly disrupts mesolimbic DA signaling in rats (Yorgason et al, 2013; Skelly et al, 2015). The KOR system modulates DA in the NAc and is involved in regulating both anxiety-like and drug-seeking behaviors (Sperling et al, 2010; Walker et al, 2012; Berger et al, 2013). Experiments in the current study examined the hypothesis that SI-induced alterations in NAc
DA signaling involve an upregulation of the dynorphin/KOR system. Consistent with our prior findings, we observed a significant SI-associated increase in evoked DA release and DA uptake in the NAc along with enhanced KOR-mediated inhibition of DA release. SI was also associated with lower baseline DA levels in the NAc, which were elevated to $\mathrm{GH}$ levels by KOR blockade. Furthermore, ethanol intake and preference were significantly enhanced in SI rats and norBNI pretreatment selectively reduced these measures in SI, but not in $\mathrm{GH}$, rats. Quantification of dynorphin levels in NAc tissue showed that dynorphin concentrations were lower in SI compared with GH animals, which may indicate greater ongoing release of dynorphin and a resulting depletion of dynorphin stores. Therefore, it is possible that SI results in a significant enhancement of KOR signaling in the NAc and that blockade of these receptors normalizes SI-associated perturbations in NAc DA levels as well as escalated ethanol intake and preference.

\section{Adolescent SI Disrupts DA Transmission in the NAc}

Many studies have demonstrated that chronic stress, particularly during adolescence, results in a dysfunctional DA system (Broom and Yamamoto, 2005; Lucas et al, 2007; Karkhanis et al, 2015), which may result in a hypodopaminergic state. A hypodopaminergic state is classically characterized by reduced extracellular DA levels (tonic) but increased electrically stimulated DA release (phasic) and uptake rates (Mathews et al, 2009). The microdialysis data in the current study documented decreased tonic extracellular DA levels in SI compared with GH animals at baseline. Extracellular levels of DA in the NAc are determined, in part, by DA transporter (DAT) activity (Ferris et al, 2014). The increased uptake of DA observed in the NAc core and shell of SI rats in the current study and in the NAc core in a previous report (Yorgason et al, 2013) suggests that SI leads to augmented DAT levels in this brain region (Yorgason et al, 2015). Interestingly, other forms of chronic stress, such as repeated restraint stress, have also been shown to enhance DA uptake in the striatum (Copeland et al, 2005) and chronic ethanol exposure increases DA uptake in adult mouse, rat, and monkey models (Budygin et al, 2003;2007; Karkhanis et al, 2015). An increase in DAT function would be expected to decrease overall extracellular DA levels. Furthermore, electrically stimulated DA release was greater in SI compared with GH animals in both the NAc core and shell, extending a prior study that had shown this effect in the core region (Yorgason et al, 2013). Electrically evoked DA release in slices models a salient stimulus-induced DA response or phasic release in a whole animal. These findings suggest that SI may lead to an augmentation of the normal NAc DA response to salient environmental stimuli (Lapiz et al, 2003). These data support the overall hypothesis that exposure to chronic early-life stress induces a hypodopaminergic state at baseline, with an associated enhancement of DA system responses to salient stimuli. Recently, it has been shown that KOR activation augments DAT activity (Kivell et al, 2014). Therefore, the remainder of our study sought to test the hypothesis that this low DA state was mediated, at least in part, by an increase in dynorphin/KOR system function. 

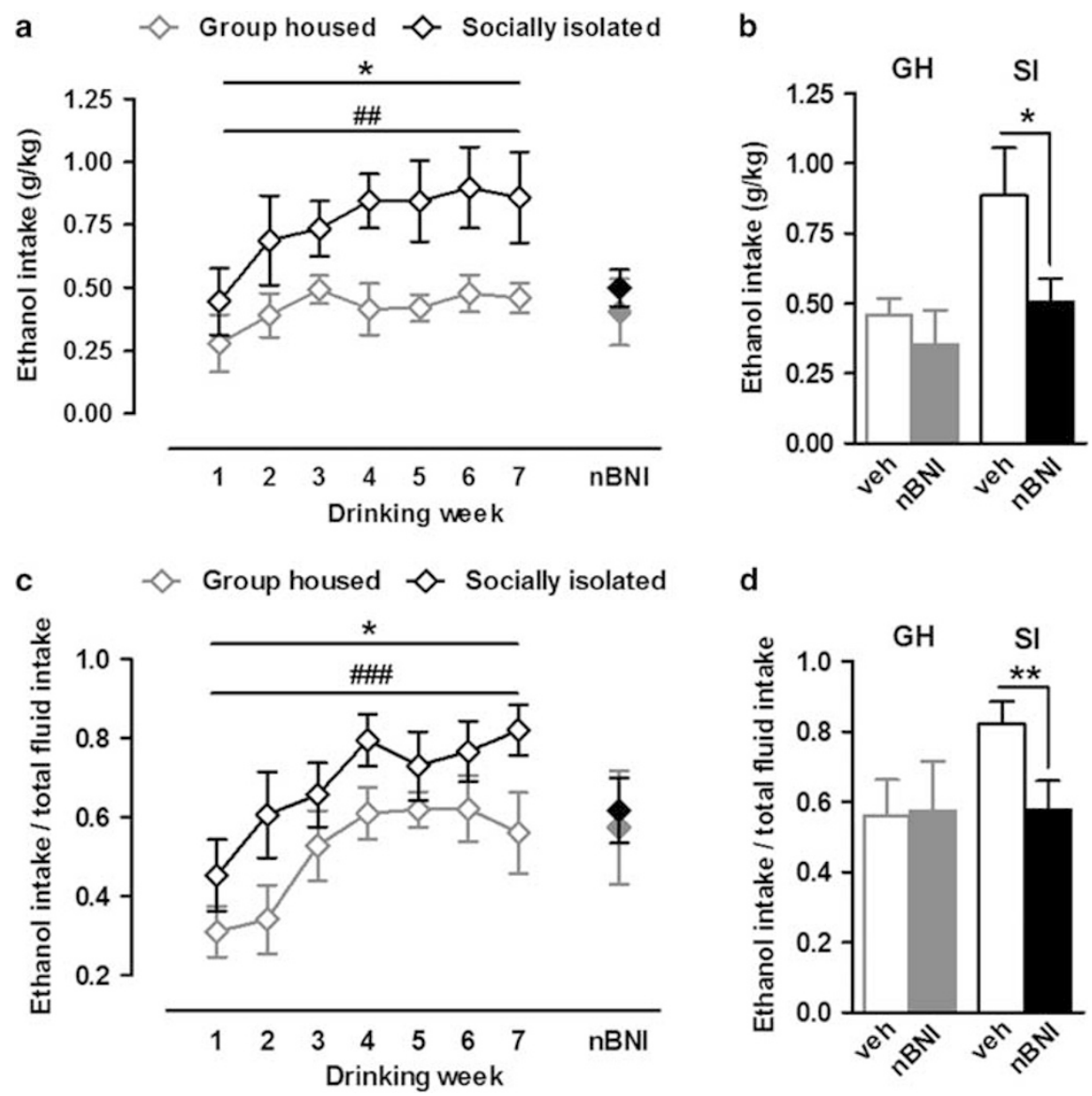

Figure 5 Ethanol intake and preference during the first 30 min following bottle exchange in $\mathrm{GH}$ and SI animals. (a) Average weekly ethanol intake and intake on the test day ( $24 \mathrm{~h}$ after nor-BNI administration). Social isolation potentiated ethanol consumption, which was reduced following nor-BNI administration. ${ }^{*} p<0.05$ (housing); ${ }^{\# \#} p<0.01$ (week). (b) Comparison of ethanol consumption before and after nor-BNI administration in GH and SI animals. KOR antagonism did not affect ethanol intake in GH animals; however, KOR blockade significantly decreased ethanol intake in SI animals. * $p<0.05$. (c) Average weekly ethanol preference over water and preference on the test day ( $24 \mathrm{~h}$ after nor-BNI administration). Social isolation facilitated ethanol preference, which was decreased following nor-BNI administration. ${ }^{*} p<0.05$ (housing); ${ }^{\# \# \# ~} p<0.00$ I (week). (d) Comparison of ethanol preference ratio before and after nor$\mathrm{BNI}$ administration in $\mathrm{GH}$ and $\mathrm{SI}$ animals. KOR antagonism did not affect preference ratio in $\mathrm{GH}$ animals. KOR blockade significantly decreased preference for ethanol in SI animals. ${ }^{*} * 2<0.01$. GH, group housed, $n=7$; SI, socially isolated, $n=8$.

\section{SI-Induced Potentiation of KOR System Responsiveness}

There is empirical evidence suggesting that repeated exposure to stress activates the dynorphin/KOR system, possibly resulting in its functional hyperactivation or supersensitivity (Walker and Koob, 2008). The voltammetric measurements of electrically evoked DA release following KOR agonist application to NAc core and shell slices in the current study support this hypothesis. KOR activation decreased DA release in the core and shell regions of NAc. These data are supported by previous findings showing a KOR activation-induced inhibition of DA release in the NAc core and shell of awake, behaving adult rats (Ebner et al, 2010). Notably, the KOR agonist-mediated decrease in DA release was greater in SI compared with GH rats in both core and shell NAc slices. These data suggest that chronic stress exposure results in functional supersensitivity of KORs. Such a change could contribute, in part, to the SI-associated decrease in baseline DA levels that was observed in the NAc.

It is also possible that changes in dynorphin levels may affect DA transmission in the NAc. In the current study, we observed that dynorphin A peptide levels measured by ELISA in NAc tissue were lower in SI compared with GH rats (Supplementary Figure S1). Lower dynorphin levels in the tissue could indicate overall low levels of intracellular and extracellular dynorphin or it could indicate that tissue levels are depleted because the extracellular levels of dynorphin are persistently high. Previous findings on stress-induced dynorphin changes are inconsistent. A recent study showed a reduction in the dynorphin mRNA levels following chronic exposure to social defeat stress in adult mice (Donahue et al, 2015). Conversely, there is evidence for increased tissue concentrations of dynorphin and dynorphin mRNA levels following repeated exposure to ethanol, which is considered a stressor, in adult rats (Lindholm et al, 2000; Kissler et al, 2014). Although the current results showing attenuated ethanol drinking and augmented baseline DA levels after nor-BNI administration selectively in SI animals could be due to nor-BNI blocking high dynorphin tone, the presence of augmented KOR agonist responses shown here and in another study (Kissler et al, 2014) would be more consistent with chronically reduced levels of endogenous 
agonist leading to compensatory supersensitivity/upregulation of receptors. A more detailed analysis will be necessary to tease apart the exact mechanisms involved; however, the current data collectively showed that KOR system responses were augmented following adolescent SI.

\section{Acute Ethanol-Induced DA Response was Enhanced Selectively in SI Rats Following KOR Blockade}

Our microdialysis studies demonstrated that acute ethanol increased extracellular DA levels in the NAc. Furthermore, DA responses were augmented selectively in SI animals pretreated with nor-BNI. In a previous study, we showed that saline administration does not result in a significant elevation of DA levels in either SI or GH animals, indicating that the ethanol-induced DA response is not driven by the injection but rather is due to the pharmacological effect of ethanol (Karkhanis et al, 2014). Ethanol has many targets, leading to both positive and negative effects on DA; however, overall, acute ethanol elevates extracellular DA levels in naive adult rats (Yim et al, 1998; Karkhanis et al, 2014). Another system that ethanol targets is the dynorphin/KOR system; acute ethanol elevates dynorphin levels in the NAc (Marinelli et al, 2006) resulting in activation of KORs, which potentially leads to a reduction in DA release. This suggests that the elevation in DA levels observed following acute ethanol administration may be buffered or dampened by the activation of KORs. However, the absence of any effect of nor-BNI in GH rats suggests that the KOR system has littleto-no effects on ethanol-stimulated DA release in control rats. Current and previous data from our laboratory show that the $1 \mathrm{~g} / \mathrm{kg}$ dose of ethanol does not differentially elevate DA in SI and GH animals (Karkhanis et al, 2014). This could be due to the suppressive effects of functionally sensitized KORs on DA selectively in SI rats. Our finding that inhibition of KORs leads to a greater effect of ethanol on $\mathrm{DA}$ release is consistent with this idea.

\section{KOR Blockade Reduces the SI-Associated Increase in Ethanol Self-Administration}

SI animals showed a long-lasting increase in ethanol intake and preference compared with GH animals, suggesting that chronic adolescent stress facilitates drug-seeking behaviors. These data are consistent with previous studies demonstrating adolescent SI-induced escalations in ethanol intake (McCool and Chappell, 2009; Chappell et al, 2013; Skelly et $a l, 2015$ ) and cocaine self-administration (Baarendse et al, 2014) in adulthood. Other stressors, such as footshock and forced swim stress, also potentiate cocaine seeking (Buffalari and See, 2009) and ethanol consumption (Sperling et al, 2010), respectively. Furthermore, repeated cycles of intermittent ethanol vapor exposure and withdrawal leads to increases in anxiety during withdrawal and an associated escalation in ethanol intake in adult mice (Griffin et al, 2009; Becker, 2012). The SI paradigm exhibits parallels to the CIE paradigm, in that, both paradigms introduce animals to stress repeatedly over fairly long periods, which results in increased drinking. It is important to note, however, that the deleterious effects of SI typically only manifest themselves when this stressor is imposed during adolescence. For example, our prior studies have demonstrated that isolating
$\mathrm{GH}$ animals for an extended period in adulthood has no effect on accumbal DA terminal kinetics nor does it lead to increases in anxiety-like behaviors (Yorgason et al, 2013). Importantly, the significant difference in ethanol drinking between adolescent SI and GH rats persists for at least 8 weeks into adulthood, even when all subjects are isolated during the drinking regimen (Skelly et al, 2015). Therefore, the KOR-dependent neurobiological and behavioral alterations observed in this study are likely due to adaptive changes that manifest during exposure to the chronic stress associated with adolescent SI.

Administration of the KOR antagonist nor-BNI decreased ethanol intake selectively in SI animals. Previous reports showed that ethanol dependence-induced escalation of ethanol intake was selectively ameliorated by KOR antagonism, whereas leaving drinking in non-dependent adult animals intact (Walker and Koob, 2008; Walker et al, 2011). These behavioral data are also consistent with the selective enhancing effect of nor-BNI on baseline DA in SI rats observed in the current study. Adult rodents exposed to chronic ethanol (Becker, 2012; Berger et al, 2013; Rose et al, 2015) and rats exposed to adolescent SI (Karkhanis et al, 2014) exhibit increased anxiety-like behaviors. Thus it is possible that escalated ethanol intake in dependent and SI rats is driven, at least in part, by a persistent elevation of stress and anxiety.

It should be noted that KOR involvement in reward processing and models of ethanol exposure in general is complicated and may lead to seemingly contradictory findings. For example, one study showed that the KOR agonist, U50,488, attenuated, rather than increased, ethanol intake in Lewis rats (Lindholm et al, 2001). However, KOR activation time-dependently modulates vulnerability to drugs of abuse and reward processing; for example, a recent study showed that administration of cocaine $15 \mathrm{~min}$ after KOR activation with salvinorin A (salA; the time point used in Lindholm et al, 2001) decreased ICSS thresholds and increased DA release, consistent with increased positive affect, while cocaine administration $24 \mathrm{~h}$ after KOR activation increased ICSS thresholds and decreased DA release, indicating a negative affective state (Chartoff et al, 2016). Finally, another study showed that nor-BNI increased ethanol intake in rats that were housed in a manner similar to GH animals in the current study (Mitchell et al, 2005). However, the increase in ethanol intake observed in that study occurred 3-6 days after nor-BNI administration. The current data are consistent with the results in the previous study (Mitchell et al, 2005) at the $24 \mathrm{~h}$ time point during which no change in ethanol intake was observed. This finding is also consistent with our microdialysis data, which found no effect of nor-BNI on baseline NAc DA levels or ethanol-stimulated DA in GH animals. These discordant findings may not only reflect a number of important methodological differences between the studies (eg, model used, concentration of ethanol, and the temporal difference between nor-BNI administration and ethanol intake test) but also highlight the fact that the relationships between KOR activity and ethanol- and stress-related neurochemistry and behavior are complex. 


\section{Therapeutic Effects of KOR Blockade}

Multiple studies have reported that KOR antagonists alleviate stress-associated reinstatement of drug seeking (Beardsley et al, 2005; Funk et al, 2014). Additionally, KOR antagonism blocks stress-induced facilitation of conditioned place preference for cocaine and alcohol (McLaughlin et al, 2006; Sperling et al, 2010). These data suggest that KOR activation is essential to drive stress-induced reward seeking and that functional upregulation of the KOR signaling increases the reinforcing efficacy of drugs of abuse, potentially through alleviation of a withdrawal-associated negative affective state. KOR antagonists reduce stress-associated escalation of ethanol intake and decrease the reinforcing efficacy of drugs of abuse (current study; Berger et al, 2013; Funk et al, 2014). Likewise, in the current study, KOR blockade increased DA levels in SI rats, thus rescuing the animals from a hypodopaminergic state. It is possible that reversing the hypodopaminergic state of an animal by blocking KORs would decrease ethanol consumption, and consistent with this hypothesis, administration of nor-BNI attenuated ethanol intake in SI animals.

\section{CONCLUSIONS}

The SI model engenders robust and enduring alterations in a wide range of behaviors associated with increased vulnerability to comorbid anxiety and AUDs. Although prior studies have suggested that a dysregulation of mesolimbic DA signaling may contribute to the SI-associated behavioral phenotype, the current study has provided compelling new data implicating the accumbal dynorphin/KOR system in the neurobiological and behavioral changes associated with this model. Results from NAc slices and freely moving animals reveal a significant increase in KOR-mediated inhibition of baseline and stimulated DA release in the NAc of SI animals. Moreover, blockade of KORs selectively reduced the escalation in ethanol intake associated with the SI model. The ability of a KOR antagonist to selectively increase baseline DA levels and attenuate ethanol intake in animals exposed to chronic early-life stress suggests that drugs targeting KORs may represent promising pharmacotherapies for the treatment of alcoholism, particularly in cases associated with comorbid anxiety disorders.

\section{FUNDING AND DISCLOSURE}

This study was funded by T32 AA007565-21 (to ANK), F31 DA03558 (to JHR), R37 AA17531 (to JLW), P01 AA021099 (to JLW and SRJ), and U01 AA014091 (to SRJ). The authors declare no conflict of interest.

\section{ACKNOWLEDGMENTS}

We thank Jason Locke and Eugenia Carter for their technical support.

\section{AUTHOR CONTRIBUTIONS}

ANK, JLW, and SRJ were responsible for the study concept and design. ANK conducted all the microdialysis and voltammetry experiments and analyzed these data. ANK and JHR conducted the ethanol drinking experiments and analyzed these data. JHR conducted the dynorphin ELISA and analyzed these data. ANK drafted the manuscript. JHR, JLW, and SRJ provided critical revision of the manuscript for important intellectual content. All authors critically reviewed content and approved the final version for publication.

\section{REFERENCES}

Anda RF, Whitfield CL, Felitti VJ, Chapman D, Edwards VJ, Dube SR et al (2002). Adverse childhood experiences, alcoholic parents, and later risk of alcoholism and depression. Psychiatr Serv 53: 1001-1009.

Baarendse PJ, Limpens JH, Vanderschuren LJ (2014). Disrupted social development enhances the motivation for cocaine in rats. Psychopharmacology 231: 1695-1704.

Beardsley PM, Howard JL, Shelton KL, Carroll FI (2005). Differential effects of the novel kappa opioid receptor antagonist, JDTic, on reinstatement of cocaine-seeking induced by footshock stressors vs cocaine primes and its antidepressant-like effects in rats. Psychopharmacology 183: 118-126.

Becker HC (2012). Effects of alcohol dependence and withdrawal on stress responsiveness and alcohol consumption. Alcohol Res 34: 448-458.

Berger AL, Williams AM, McGinnis MM, Walker BM (2013). Affective cue-induced escalation of alcohol self-administration and increased $22-\mathrm{kHz}$ ultrasonic vocalizations during alcohol withdrawal: role of kappa-opioid receptors. Neuropsychopharmacology 38: 647-654.

Borland LM, Shi G, Yang H, Michael AC (2005). Voltammetric study of extracellular dopamine near microdialysis probes acutely implanted in the striatum of the anesthetized rat. J Neurosci Methods 146: 149-158.

Broom SL, Yamamoto BK (2005). Effects of subchronic methamphetamine exposure on basal dopamine and stress-induced dopamine release in the nucleus accumbens shell of rats. Psychopharmacology 181: 467-476.

Bruchas MR, Land BB, Chavkin C (2010). The dynorphin/kappa opioid system as a modulator of stress-induced and pro-addictive behaviors. Brain Res 1314: 44-55.

Budygin EA, John CE, Mateo Y, Daunais JB, Friedman DP, Grant KA et al (2003). Chronic ethanol exposure alters presynaptic dopamine function in the striatum of monkeys: a preliminary study. Synapse 50: 266-268.

Budygin EA, Oleson EB, Mathews TA, Lack AK, Diaz MR, McCool BA et al (2007). Effects of chronic alcohol exposure on dopamine uptake in rat nucleus accumbens and caudate putamen. Psychopharmacology 193: 495-501.

Buffalari DM, See RE (2009). Footshock stress potentiates cueinduced cocaine-seeking in an animal model of relapse. Physiol Behav 98: 614-617.

Chappell AM, Carter E, McCool BA, Weiner JL (2013). Adolescent rearing conditions influence the relationship between initial anxiety-like behavior and ethanol drinking in male Long Evans rats. Alcohol Clin Exp Res 37(Suppl 1): E394-E403.

Chartoff EH, Ebner SR, Sparrow A, Potter D, Baker PM, Ragozzino ME et al (2016). Relative timing between kappa opioid receptor activation and cocaine determines the impact on reward and dopamine release. Neuropsychopharmacology 41: 989-1002.

Chavkin C, James IF, Goldstein A (1982). Dynorphin is a specific endogenous ligand of the kappa opioid receptor. Science 215: 412-415.

Copeland BJ, Neff NH, Hadjiconstantinou M (2005). Enhanced dopamine uptake in the striatum following repeated restraint stress. Synapse 57: 167-174. 
Di Chiara G, Imperato A (1988). Drugs abused by humans preferentially increase synaptic dopamine concentrations in the mesolimbic system of freely moving rats. Proc Natl Acad Sci USA 85: 5274-5278.

Donahue RJ, Landino SM, Golden SA, Carroll FI, Russo SJ, Carlezon WA Jr. (2015). Effects of acute and chronic social defeat stress are differentially mediated by the dynorphin/kappa-opioid receptor system. Behav Pharmacol 26: 654-663.

Ebner SR, Roitman MF, Potter DN, Rachlin AB, Chartoff EH (2010). Depressive-like effects of the kappa opioid receptor agonist salvinorin A are associated with decreased phasic dopamine release in the nucleus accumbens. Psychopharmacology 210: 241-252.

Ferris MJ, Calipari ES, Yorgason JT, Jones SR (2013). Examining the complex regulation and drug-induced plasticity of dopamine release and uptake using voltammetry in brain slices. ACS Chem Neurosci 4: 693-703.

Ferris MJ, España RA, Locke JL, Konstantopoulos JK, Rose JH, Chen $\mathrm{R}$ et al (2014). Dopamine transporters govern diurnal variation in extracellular dopamine tone. Proc Natl Acad Sci USA 111: E2751-E2759.

Funk D, Coen K, Lê AD (2014). The role of kappa opioid receptors in stress-induced reinstatement of alcohol seeking in rats. Brain Behav 4: 356-367.

Gershon A, Sudheimer K, Tirouvanziam R, Williams LM, O'Hara R (2013). The long-term impact of early adversity on late-life psychiatric disorders. Curr Psychiatry Rep 15: 352.

Griffin WC 3rd, Lopez MF, Yanke AB, Middaugh LD, Becker HC (2009). Repeated cycles of chronic intermittent ethanol exposure in mice increases voluntary ethanol drinking and ethanol concentrations in the nucleus accumbens. Psychopharmacology 201: 569-580.

John CE, Jones SR (2007). Voltammetric characterization of the effect of monoamine uptake inhibitors and releasers on dopamine and serotonin uptake in mouse caudate-putamen and substantia nigra slices. Neuropharmacology 52: 1596-1605.

Karkhanis AN, Locke JL, McCool BA, Weiner JL, Jones SR (2014). Social isolation rearing increases nucleus accumbens dopamine and norepinephrine responses to acute ethanol in adulthood. Alcohol Clin Exp Res 38: 2770-2779.

Karkhanis AN, Rose JH, Huggins KN, Konstantopoulos JK, Jones SR (2015). Chronic intermittent ethanol exposure reduces presynaptic dopamine neurotransmission in the mouse nucleus accumbens. Drug Alcohol Depend 150: 24-30.

Kissler JL, Sirohi S, Reis DJ, Jansen HT, Quock RM, Smith DG et al (2014). The one-two punch of alcoholism: role of central amygdala dynorphins/kappa-opioid receptors. Biol Psychiatry 75: $774-782$

Kivell B, Uzelac Z, Sundaramurthy S, Rajamanickam J, Ewald A, Chefer V et al (2014). Salvinorin A regulates dopamine transporter function via a kappa opioid receptor and ERK1/2dependent mechanism. Neuropharmacology 86: 228-240.

Koob GF, Buck CL, Cohen A, Edwards S, Park PE, Schlosburg JE et al (2014). Addiction as a stress surfeit disorder. Neuropharmacology 76: 370-382.

Land BB, Bruchas MR, Lemos JC, Xu M, Melief EJ, Chavkin C (2008). The dysphoric component of stress is encoded by activation of the dynorphin kappa-opioid system. J Neurosci 28: 407-414.

Lapiz MD, Fulford A, Muchimapura S, Mason R, Parker T, Marsden CA (2003). Influence of postweaning social isolation in the rat on brain development, conditioned behavior, and neurotransmission. Neurosci Behav Physiol 33: 13-29.

Lindholm S, Ploj K, Franck J, Nylander I (2000). Repeated ethanol administration induces short- and long-term changes in enkephalin and dynorphin tissue concentrations in rat brain. Alcohol 22: 165-171.

Lindholm S, Werme M, Brené S, Franck J (2001). The selective kappa-opioid receptor agonist $\mathrm{U} 50,488 \mathrm{H}$ attenuates voluntary ethanol intake in the rat. Behav Brain Res 120: 137-146.
Lucas LR, Wang CJ, McCall TJ, McEwen BS (2007). Effects of immobilization stress on neurochemical markers in the motivational system of the male rat. Brain Res 25: 108-115.

Marinelli PW, Lam M, Bai L, Quirion R, Gianoulakis C (2006). A microdialysis profile of dynorphin $\mathrm{A}(1-8)$ release in the rat nucleus accumbens following alcohol administration. Alcohol Clin Exp Res 30: 982-990.

Mathews TA, Brookshire BR, Budygin EA, Hamre K, Goldowitz D, Jones SR (2009). Ethanol-induced hyperactivity is associated with hypodopaminergia in the 22-TNJ ENU-mutated mouse. Alcohol 43: 421-431.

McCool BA, Chappell AM (2009). Early social isolation in male Long-Evans rats alters both appetitive and consummatory behaviors expressed during operant ethanol self-administration. Alcohol Clin Exp Res 33: 273-282.

McLaughlin JP, Land BB, Li S, Pintar JE, Chavkin C (2006). Prior activation of kappa opioid receptors by U50,488 mimics repeated forced swim stress to potentiate cocaine place preference conditioning. Neuropsychopharmacology 31: 787-794.

Mitchell JM, Liang MT, Fields HL (2005). A single injection of the kappa opioid antagonist norbinaltorphimine increases ethanol consumption in rats. Psychopharmacology 182: 384-392.

Nabeshima T, Katoh A, Wada M, Kameyama T (1992). Stressinduced changes in brain Met-enkephalin, Leu-enkephalin and dynorphin concentrations. Life Sci 51: 211-217.

Paxinos G, Watson C (2007). The Rat Brain in Stereotaxic Coordinates, 6th edn. Elsevier Inc.: Burlington, MA.

Radke AK, Gewirtz JC (2012). Increased dopamine receptor activity in the nucleus accumbens shell ameliorates anxiety during drug withdrawal. Neuropsychopharmacology 37: 2405-2415.

Rose JH, Karkhanis AN, Chen R, Gioia D, Lopez MF, Becker HC et al (2015). Supersensitive kappa opioid receptors promotes ethanol withdrawal-related behaviors and reduce dopamine signaling in the nucleus accumbens. Int J Neuropsychopharmacol, (e-pub ahead of print).

Schlosburg JE, Whitfield TW Jr, Park PE, Crawford EF, George O, Vendruscolo LF et al (2013). Long-term antagonism of $\kappa$ opioid receptors prevents escalation of and increased motivation for heroin intake. J Neurosci 33: 19384-19392.

Simms JA, Steensland P, Medina B, Abernathy KE, Chandler LJ, Wise $\mathrm{R}$ et al (2008). Intermittent access to $20 \%$ ethanol induces high ethanol consumption in Long-Evans and Wistar rats. Alcohol Clin Exp Res 32: 1816-1823.

Skelly MJ, Chappell AE, Carter E, Weiner JL (2015). Adolescent social isolation increases anxiety-like behavior and ethanol intake and impairs fear extinction in adulthood: possible role of disrupted noradrenergic signaling. Neuropharmacology 97: 149-159.

Sperling RE, Gomes SM, Sypek EI, Carey AN, McLaughlin JP (2010). Endogenous kappa-opioid mediation of stress-induced potentiation of ethanol-conditioned place preference and selfadministration. Psychopharmacology (Berl) 210: 199-209.

Strine TW, Dube SR, Edwards VJ, Prehn AW, Rasmussen S, Wagenfeld $\mathrm{M}$ et al (2012). Associations between adverse childhood experiences, psychological distress, and adult alcohol problems. Am J Health Behav 36: 408-423.

Sulzer D (2011). How addictive drugs disrupt presynaptic dopamine neurotransmission. Neuron 69: 628-649.

Suto N, Ecke LE, You ZB, Wise RA (2010). Extracellular fluctuations of dopamine and glutamate in the nucleus accumbens core and shell associated with lever-pressing during cocaine self-administration, extinction, and yoked cocaine administration. Psychopharmacology (Berl) 211: 267-275.

Svingos AL, Chavkin C, Colago EE, Pickel VM (2001). Major coexpression of kappa-opioid receptors and the dopamine transporter in nucleus accumbens axonal profiles. Synapse 42: 185-192. 
Walker BM, Koob GF (2008). Pharmacological evidence for a motivational role of kappa-opioid systems in ethanol dependence. Neuropsychopharmacology 33: 643-652.

Walker BM, Valdez GR, McLaughlin JP, Bakalkin G (2012). Targeting dynorphin/kappa opioid receptor systems to treat alcohol abuse and dependence. Alcohol 46: 359-370.

Walker BM, Zorrilla EP, Koob GF (2011). Systemic $\kappa$-opioid receptor antagonism by nor-binaltorphimine reduces dependence-induced excessive alcohol self-administration in rats. Addict Biol 16: 116-119.

Werling LL, Frattali A, Portoghese PS, Takemori AE, Cox BM (1988). Kappa receptor regulation of dopamine release from striatum and cortex of rats and guinea pigs. J Pharmacol Exp Ther 246: 282-286.

Wise RA (1973). Voluntary ethanol intake in rats following exposure to ethanol on various schedules. Psychopharmacologia 29: 203-210.

Woods SK, Meyer JS (1991). Exogenous tyrosine potentiates the methylphenidate-induced increase in extracellular dopamine in the nucleus accumbens: a microdialysis study. Brain Res 560: 97-105.

Yim HJ, Schallert T, Randall PK, Gonzales RA (1998). Comparison of local and systemic ethanol effects on extracellular dopamine concentration in rat nucleus accumbens by microdialysis. Alcohol Clin Exp Res 22: 367-374.

Yorgason JT, Calipari ES, Ferris MJ, Karkhanis AN, Fordahl SC, Weiner JL et al (2015). Social isolation rearing increases dopamine uptake and psychostimulant potency in the striatum. Neuropharmacology 101: 471-479.

Yorgason JT, Espana RA, Jones SR (2011). Demon voltammetry and analysis software: analysis of cocaine-induced alterations in dopamine signaling using multiple kinetic measures. J Neurosci Methods 202: 158-164.

Yorgason JT, Espana RA, Konstantopoulos JK, Weiner JL, Jones SR (2013). Enduring increases in anxiety-like behavior and rapid nucleus accumbens dopamine signaling in socially isolated rats. Eur J Neurosci 37: 1022-1031.

Supplementary Information accompanies the paper on the Neuropsychopharmacology website (http://www.nature.com/npp) 